\title{
Neurophysiology of a Central Baroreceptor Pathway Projecting to Hypothalamic Vasopressin Neurons
}

\author{
Jack H. Jhamandas and Leo P. Renaud
}

\begin{abstract}
Controversy exists as to the neural network whereby peripheral arterial baroreceptor information is transmitted to vasopressin (VP)-secreting neurons of the hypothalamic supraoptic nucleus (s.o.n.). In vivo electrophysiological studies in the rat were undertaken to characterize the selective depression of VP cell activity consequent to activation of peripheral baroreceptors. Electrical stimulation of the diagonal band of Broca (DB) in the rat evoked a similar selective inhibition of vasopressinergic neurons of the s.o.n. Local application of bicuculline, a GABA antagonist, abolished both the DB-evoked and baroreceptor-induced inhibition of VP-secreting neurons. In addition, recordings from DB neurons antidromically activated from the s.o.n. displayed an increase in firing consequent to baroreceptor activation, coinciding with the suppression of firing in s.o.n. VP neurons. These observations collectively indicate that an intrinsic GABA projection arising in the DB cell group selectively inhibits vasopressinergic neurons of the s.o.n. and that this pathway mediates peripheral arterial baroreceptor activity that influences the release of VP in the neurohypophysis. These data may be of critical importance in our understanding the etiology of those forms of experimental hypertension where abnormalities in central baroreceptor pathways have been implicated but not proven.
\end{abstract}

RÉSUMÉ: Neurophysiologie d'une voie centrale baroréceptrice se projetant sur les neurones vasopressinergiques de l'hypothalamus Il existe une controverse concernant le réseau nerveux par lequel l'information provenant des barorécepteurs périphériques artériels est transmise aux neurones secrétant la vasopressine (VP) au niveau du noyau hypothalamique supra-optique (n.s.o.). Des études électrophysiologiques in vivo chez le rat ont été entreprises pour caractériser la dépression sélective de l'activité des cellules VP à la suite de l'activation des barorécepteurs périphériques. La stimulation électrique de la bande diagonale de Broca (BD) chez le rat a provoqué une inhibition sélective similaire des neurones vasopressinergiques du n.s.o. L'application locale de bicuculline, un antagoniste du GABA, a aboli l'inhibition des neurones secrétant de la VP provoquée par la stimulation de la BD et celle induite par les barorécepteurs. De plus, des enregistrments faits à partir de neurones activés antidromiquement à partir du n.s.o. montrent une augmentation des décharges à la suite de l'activation des barorécepteurs, coïncidant avec la suppression des décharges des neurones VP dans le n.s.o. L'ensemble de ces observations indique qu'une projection intrinsèque $\mathrm{GABA}$, originant dans le groupe cellulaire de la $\mathrm{BD}$, inhibe sélectivement les neurones vasopressinergiques du n.s.o. et que cette voie transmet l'activité des barorécepteurs artériels périphériques qui influence la libération de la VP dans la neurohypophyse. Ces données peuvent avoir une importance capitale dans notre compréhension de l'étiologie des formes d'hypertension expérimentale où on a impliqué, sans les prouver, des anomalies des voies baroréceptrices centrales.

Can. J. Neurol. Sci. 1987; 14:17-24

The hypothalamic supraoptic nucleus (s.o.n.) contains neurons that synthesize either vasopressin (VP) or oxytocin (OXY) and that project almost exclusively to the neurohypophysis. These neurons receive an abundance of afferent connections but the VP-secreting neurons in particular receive a prominent and selective input that is of cardiovascular origin. Specifically, the release of vasopressin from the neurohypophysis is effected by changes in blood pressure and blood volume as well as changes in osmolarity. ${ }^{1,2}$ The hemodynamic information concerned with this release of vasopressin is conveyed by baroreceptors located in peripheral arteries, the atria of the heart, the aortic arch and the carotid sinus. Activation of these receptors consequent to an acute elevation in blood pressure leads to an inhibition of vasopressin release from the neurohypophysis.

This paper is based on a special presentation given at the Canadian Congress of Neurological Sciences in London. Ontario in June 1986.

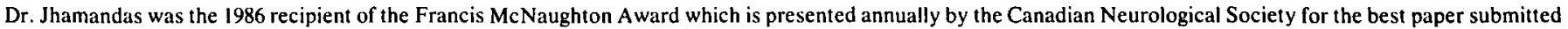
by a junior member of the society.

From the Neurosciences Unit, Montreal General Hospital and McGill University, 1650 Cedar Ave., Montreal, Quebec

Reprint requests to: Dr. Jack H. Jhamandas, Division of Neurology, Montreal General Hospital Research Inst., 1650 Cedar Avenue, Montreal, Quebec. Canada H3G 1 A4 
The electrophysiological correlate of this diminished hormone release is reflected in a decrement in firing frequency of VP-synthesizing neurons of the s.o.n.

The neuroanatomical pathways whereby cardiovascular information reaches and is processed within the central nervous system have been the focus of much recent attention. While it seems clear that baroreceptor input is conveyed to the dorsomedial medulla, specifically to the nucleus tractus solitarius via the glossopharyngeal and vagus nerves, the neuronal network for subsequent transmission of this information to the level of the hypothalamus remains poorly understood. The observation that ipsilateral lesions of the locus coeruleus interrupt baroreceptor input to s.o.n. vasopressinergic cells ${ }^{3}$ supports the involvement of an ascending noradrenergic pathway. However, it would appear that noradrenergic neurons are unlikely to convey baroreceptor activated input directly to vasopressinergic cells since baroreceptor input remains after 6-hydroxydopamine-induced depletion of the terminal catecholamine histofluorescence in the s.o.n. ${ }^{4}$ In view of evidence that noradrenaline and noradrenergic afferents facilitate, rather than depress, the firing of VP-secreting cells ${ }^{5,6}$ one can postulate some other inhibitory transmitter system is interposed in the baroreflex pathway. We now report 1) that diagonal band of Broca (DB) neurons which project to the s.o.n. are responsive to baroreceptor activation; 2) that this DB input is inhibitory, probably GABAergic and selectively influences the excitability of vasopressinergic neurons; 3 ) that bicuculline, a GABA antagonist, abolishes the baroreceptor induced inhibition of vasopressinergic neurons. It is proposed that this DB-s.o.n. projection mediates baroreceptor induced suppression of vasopressin release from the neurohypophysis.

\section{METHODS}

\section{Surgical preparation}

Male Long-Evans rats (150-250 g) were anesthetized initially with intraperitoneal sodium pentobarbital $(50 \mathrm{mg} / \mathrm{kg})$ and maintained with supplemental doses of $2-4 \mathrm{mg}$ given into the external jugular every 1-3 hrs. The femoral artery and vein were catherterized so as to record blood pressure and administer a peripheral vasoconstrictor (metaraminol, 2-10 ug) respectively. Heart rate was monitored continuously and body temperature was maintained at $37^{\circ} \mathrm{C}$. Following tracheal intubation the ventral surface of the hypothalamus was surgically exposed using the transpharyngeal approach.

\section{Electrophysiology}

\section{A) Neurosecretory neurons}

Neurosecretory cells in the s.o.n. were identified by antidromic activation following stimulation (pulse duration $0.05 \mathrm{~ms}$, intensity $<1 \mathrm{~mA}$ ) of their axon terminals in the neurohypophysis (Figure 1A). Extracellular recordings were obtained through micropipettes (10-20 $\mathrm{M} \Omega$ impedance) filled with $3.0 \mathrm{M}$ potassium acetate, amplified conventionally, bandpass filtered, displayed on an oscilloscope and led through a window discriminator to an on line PDP 11/23 computer programmed for spike train analysis.

Cathodal pulses $(0.05 \mathrm{~ms}$ duration, $100-400 \mu \mathrm{A})$ were delivered to the area of the diagonal band of Broca through a monopolar, glass-insulated tungsten electrode (tip exposure $75-100 \mu \mathrm{m}$, base diameter $25-50 \mu \mathrm{m}$ ) mounted on a micromani- pulator and inserted through the ventral exposure. The anode was attached to the exposed jaw muscles. The stimulation current was verified by measuring the voltage drop across a $100 \mathrm{k} \Omega$ resistor placed in series with the stimulating electrode.

\section{B) Diagonal band of Broca $(D B)$ neurons}

Extracellular recordings from DB neurons were obtained in the manner similar to that described above for neurosecretory cells. Monopolar cathodal stimulation ( $0.05 \mathrm{~ms}$ duration) was, in this instance, applied to the SON in order to antidromically activate DB neurons. Peripheral arterial baroreceptors were activated by intravenous administration of the alpha-agonist metaraminol $(2-10 \mu \mathrm{g})$ sufficient to acutely raise blood pressure by $40-60 \mathrm{~mm} \mathrm{Hg}$.

\section{Classification of s.o.n. neurosecretory cells}

In the rat, neurosecretory cells located in either the s.o.n. or p.v.n. may exhibit irregular, continuous or phasic firing.' As reported previously, ${ }^{5.7}$ the further classification of neurosecretory neurones into putative VP-secreting or OXY-secreting cells depends on their response to activation of peripheral baroreceptors, achieved by raising arterial blood pressure with a brief intravenous infusion of metaraminol. Thus, in this study, units demonstrating phasic or continuous activity that was transiently suppressed by this manouver were classified as VP-secreting; those whose continuous firing was unresponsive to baroreceptor activation were classified as $\mathrm{OXY}$-secreting (Figure 1B).

\section{Pharmacology}

Drugs to be applied to single neurones by pressure ejection (cf. Day et al. ${ }^{6}$ ) included bicuculline methiodide (BMI, Sigma, $100 \mu \mathrm{M})$, strychnine sulfate $(100 \mu \mathrm{M})$, prazosin hydrochloride $(10 \mu \mathrm{M})$ and timolol maleate $(20 \mu \mathrm{M})$. Each drug was dissolved in $0.9 \% \mathrm{NaCl}$ at the time of experiment; prazosin was dissolved in dimethylsulfoxide prior to dilution in saline. Drugs were ejected by a pressure device (Picospritzer, General Valve Corp., New Jersey) using 1-20 psi applied to single channels of a 3-barrel micropipette whose tip (total diam. 2.5-10 $\mu \mathrm{m}$ ) was set back from that of the recording electrode by 30-50 $\mu \mathrm{m}$. Possible pressure-related effects were assessed by careful monitoring of spike amplitude; whenever spike amplitude changed abruptly consequent to the application of a pressure pulse, the data were excluded from further data analysis. Drug concentrations refer to the intrabarrel composition; one would expect considerable dilution immediately upon ejection from the micropipette tip.

\section{Histology}

At the conclusion of each experiment the location of the stimulating electrode tip in the diagonal band of Broca and the s.o.n. was marked by a small anodal lesion ( $200 \mu$ A d.c., 10 s). Animals were deeply anesthetized and perfused through the heart with saline followed by $10 \%$ formaldehyde. Stimulation sites were identified in $50 \mu \mathrm{m}$ serial sections of the brain cut with a vibratome and stained with thionin.

\section{RESULTS}

\section{Diagonal band of Broca Stimulation}

Data from 135 antidromically identified and spontaneously active neurosecretory neurones included 113 classified as puta- 
A

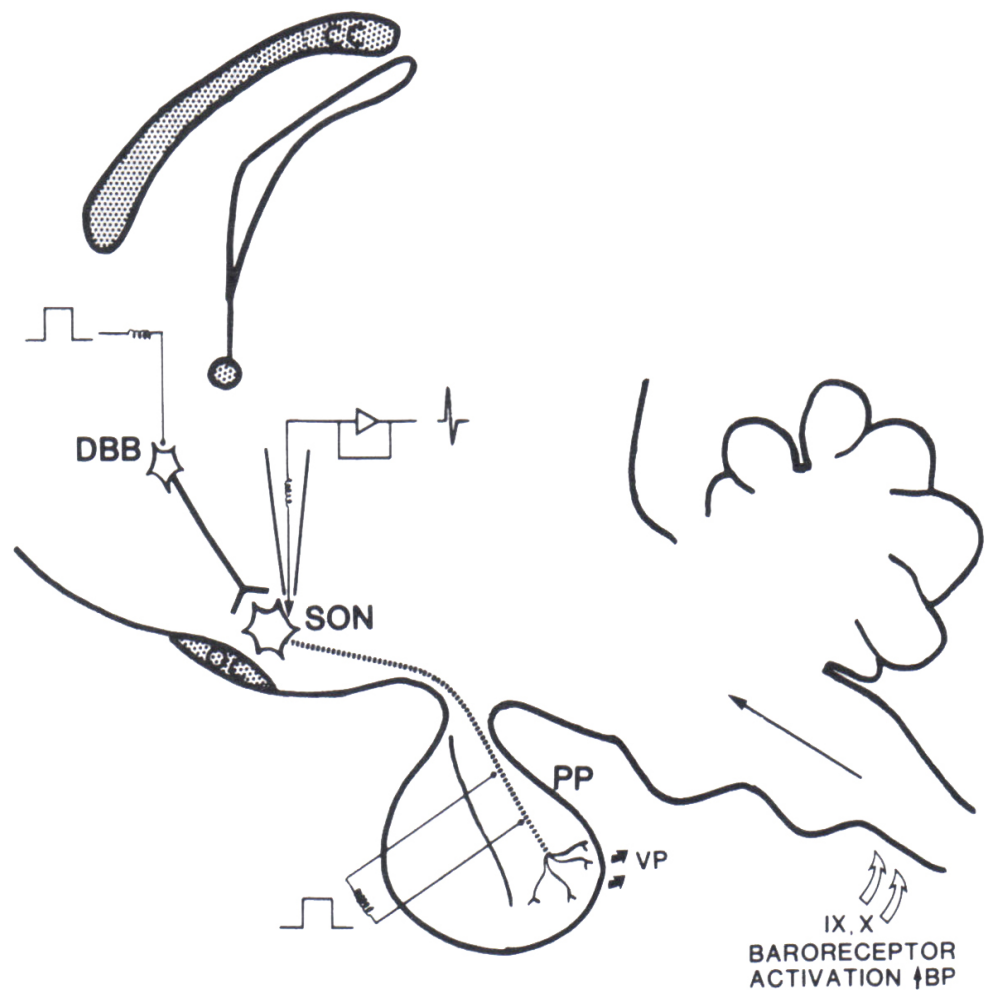

B

SON, putative VP neuron
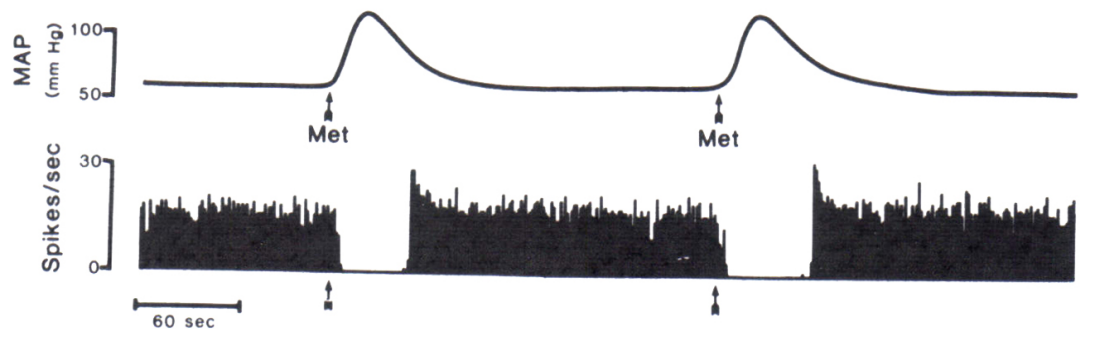

SON, putative OXY neuron
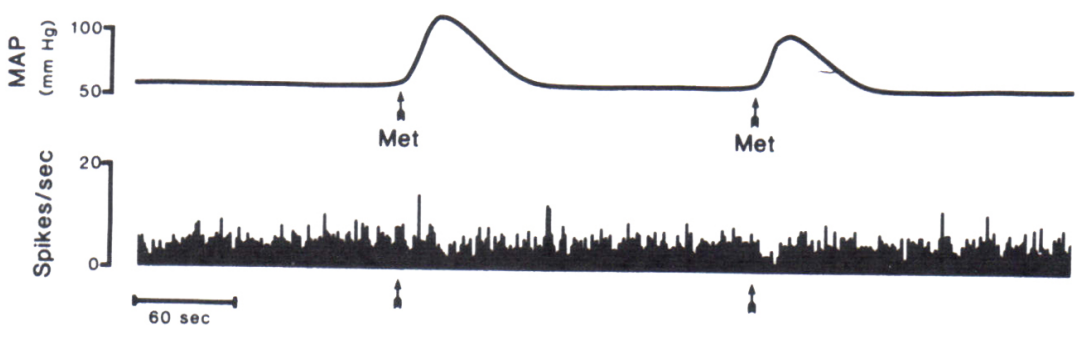

Figure I - (A) Schematic of the rat brain (sagittal section) to illustrate the set-up for recording from the supraoptic nucleus (SON) in vivo. Neurosecretory cells were antidromically identified by stimulation of their terminals in the posterior pituitary $(P P)$. The vasopressin (VP) and oxytocin (OXY) neurons were distinguished as shown in $B$ and the influence of diagonal band of Broca $(D B)$ stimulation on the excitability of SON neurons were assessed. $(B)$ Ratemeter and corresponding blood pressure records illustrate the differences between VP and OXY neurons of the SON. Top trace: a continously active putative VP-secreting cell is inhibited by baroreceptor activation consequent to an acute rise in blood pressure which was achieved by a brief, intravenous infusion of $0.1 \%$ metaraminol (Met). Bottom trace: another continuously active cell that is unresponsive to baroreceptor activation is classified as a putative OXY-secreting cell. 
tive VP neurons and 22 classified as putative OXY neurones. The responses to diagonal band of Broca stimulation differentially influenced the excitability of cells in each group.

Among the putative VP cell population, stimulation sites confined to the ventral half of the diagonal band of Broca (Figure $2 \mathrm{~A}$ ) altered the excitability of $83 \%$ of neurons. Responses uniformly consisted of a short latency (mean $8.6 \pm 0.9 \mathrm{~ms}$, SE of mean) reduction in excitability (Figure $2 \mathrm{~B}$ ) lasting up to $100 \mathrm{~ms}$ (mean $49.0 \pm 3.2 \mathrm{~ms}$ ) could be evoked by currents of 100 uA or less.

These observations contrasted sharply with data obtained from putative OXY-neurones where the majority (59\%) were unaffected by stimulation with identical (or higher) magnitudes at the same locations. Only $14 \%$ of OXY neurones displayed responses that resembled those seen in VP cells while the remaining $27 \%$ demonstrated a prolonged (range $80-200 \mathrm{~ms}$; mean $147.0 \pm 16.8 \mathrm{~ms}$ ) increase in excitability at latencies between 15 and $60 \mathrm{~ms}$ (mean $41.0 \pm 7.4 \mathrm{~ms}$ ) (Figure 2C). On no occasion was the nature of an $\mathrm{OXY}$-cell response changed by alteration in stimulus intensity.
For comparison, 10 unidentified (i.e. non-neurosecretory) neurones located in the immediate vicinity of the s.o.n. were also tested. Six of these cells displayed an increase in excitability, with either long or short duration responses (not shown).

\section{DB recordings}

In ten experiments, a total of $35 \mathrm{DB}$ neurons demonstrated antidromic activation from the s.o.n. stimulation site (Figure 3B). Antidromic latencies ranged between 1.5 and $12.0 \mathrm{msec}$, with thresholds between 50 and $150 \mu \mathrm{A}$. Twelve neurons were recorded during baroreceptor activation. Of these, $50 \%$ revealed an increase in firing frequency co-incident with an acute rise in arterial pressure (Figure $3 \mathrm{~A}$ ), with activity returning to control levels as the change in blood pressure reverted to control values. Cells were located throughout the vertical limb of the DB (Figure 3B).

\section{Effects of bicuculline on stimulus-evoked inhibition}

Biochemical and immunohistochemical studies ${ }^{8.9}$ reveal evidence for the presence of $\gamma$-aminobutyric acid (GABA) in the region of the s.o.n. and in combination with GABA's depres-

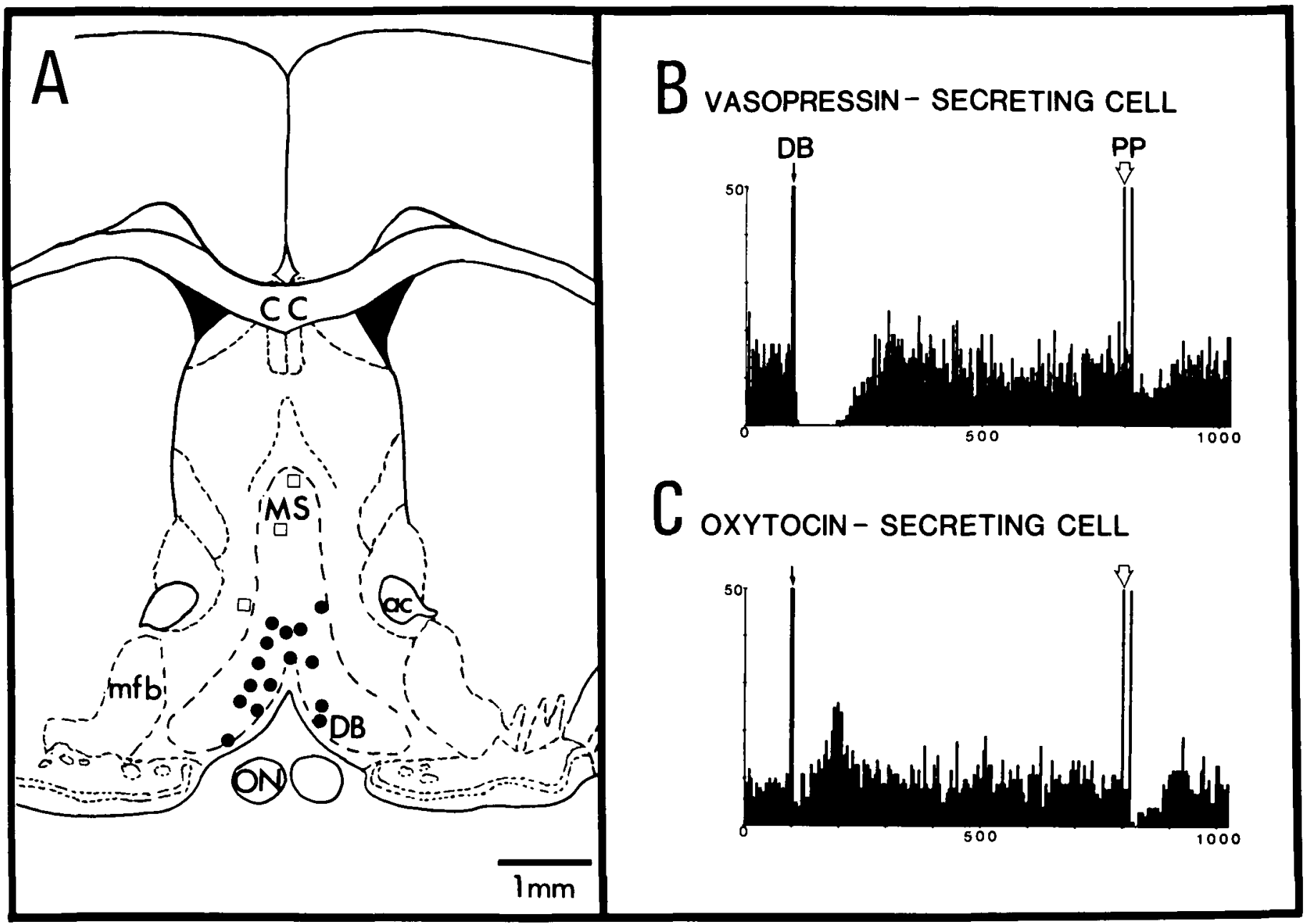

Figure $2-$ (A) Schematic coronal section of the rat brain depicting the location of electrode tips in the DB and medial septum (MS) where stimulation evoked a reduction in excitability of s.o.n. VP neurons $(\bullet)$ or was without effect $(\square)$. Abbreviations: $O N$, optic nerve: mfb, median forebrain bundle; ac, anterior commissure; $C C$, corpus callosum. $(B, C)$ Peri-stimulus histograms display the contrasting response of s.o.n. neurons to single shock stimulation $(<100$ uA $)$ in the diagonal band $(D B$, filled arrow) and the antidromic response to a posterior pituitary stimulus $(P P)$. In $B$, note the prominant reductions in excitability after $D B$ stimulation. In C, data from an $O X Y$ neuron illustrates a long duration, low probability increase in excitation after DB stimulation. I Resolution 4.0 ins per bin. 


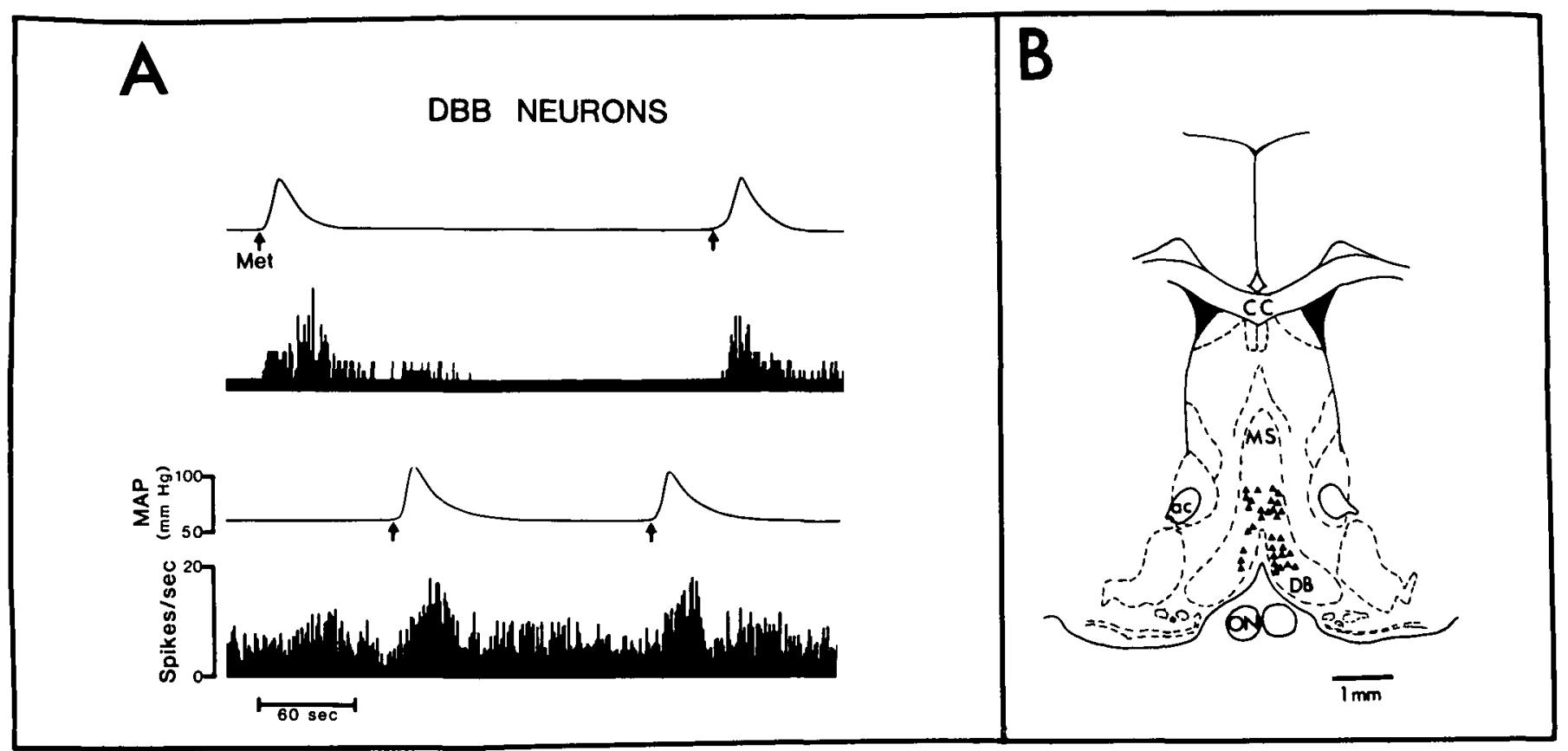

Figure 3 - (A) Simultaneous arterial pressure (upper) and ratemeter records (lower) from wo different DB cells. Note that each increase in arterial pressure consequent to intravenous administration of metaraminol (arrow) may be associated with the appearance of firing in an otherwise silent cell (above) or a further increase in the activity of a spontaneously active cell (below). (B) Symbols ( $\boldsymbol{\Delta}$ ) superimposed on a schematic coronal section of the brain depict the approximately $( \pm 100 \mu \mathrm{m})$ location of a population of neurons that displayed antidromic activation in response to SON stimulation. Abbreviations: $D B=$ diagonal band of Broca, $O N=$ optic nerve, ac = anterior commissure, $M S=$ medial septum, $C C=$ corpus callosum.

sant action on s.o.n. neurons ${ }^{10.11}$ provide a rationale for its use in the present study. GABA's contribution to the suppressant effects of DB stimulation on VP-neurons was evaluated by examining whether the evoked response pattern could be altered through local application of the GABA antagonist bicuculline. In $20 / 20$ cells tested, bicuculline reversibly abolished the stimulusevoked inhibition and in 6 cells, unmasked a late onset, long duration increase in excitability (Figure 4). Strychnine was unable to block the DB-evoked synaptic response in any of 5 cells tested.

\section{Bicuculline and baroreceptor-induced inhibition}

The ability of bicuculline to alter the suppression in firing of VP neurons consequent to a brief rise in arterial pressure was also examined. In $5 / 5$ cells tested, bicuculline applied concomitant with activation of peripheral arterial baroreceptors reversibly suppressed their anticipated reduction in firing (Figure 5). Failure to obtain similar results with application of prazosin ( $6 / 6$ cells), timolol ( $6 / 6$ cells) and strychnine ( $3 / 3$ cells) attested to the selectivity of bicuculline's blockade of the evoked response.

\section{Discussion}

Our present results demonstrate that electrical stimulation in DB activates an inhibitory projection that is directed principally to the vasopressinergic cell population in the s.o.n. Although these effects may be due to activation of fibers of passage arising in other structures where electrical stimulation can depress the excitability of s.o.n. neurons, notably the lateral septum ${ }^{12,13}$ and nucleus accumbens, ${ }^{14}$ available evidence mitigates against such a proposal. First, the data from the studies cited reveal an inhibition of both vasopressin and oxytocin neurons. Secondly, recent anatomical reports indicate that in the rat, DB consti- tutes a source of afferents to the s.o.n. ${ }^{15.16}$ Finally, the present electrophysiological data corroborate the morphological evidence cited for a DB - s.o.n. projection. The most likely explanation therefore is that our stimuli activated an inhibitory pathway that arises in the DB.

GABA is viewed as a major central inhibitory neurotransmitter candidate. ${ }^{17}$ The s.o.n. and adjacent structures contain a plexus of GABAergic fibers that make synaptic contacts with s.o.n. neurons. ${ }^{9,18}$ In addition, biochemical and immunohistochemical studies reveal that neurons containing glutamate decarboxylase (GAD) and GABA-transaminase, the enzymes responsible for synthesizing and metabolizing GABA respectively, are present not only in the perinuclear zone of the s.o.n. ${ }^{18}$ but also extend rostrally to and beyond the diagonal band. ${ }^{19,20}$ Iontophoretic application of GABA depresses the excitability of s.o.n. cells in vivo ${ }^{10.11}$ and intracellular recordings in vitro from these same neurons reveal spontaneous and DB-evoked inhibitory post-synaptic potentials (i.p.s.ps) that are GABA mediated. ${ }^{21}$ Furthermore, reports addressing the functional role for GABA in the hypothalamus reveal GABA may affect vasopressin release. In conscious rats, central administration of large doses of GABA reduced the increase in plasma vasopressin produced by polyethylene glycol-induced hypovolemia. ${ }^{22}$ The ability therefore of locally applied bicuculline, a true GABA antagonist, to block the DB-evoked inhibition of s.o.n. VP neurons is consistent with the notion of GABA as one of the principal inhibitory neurotransmitters that regulate vasopressin release from the neurohypophysis.

A selectivity of excitatory or inhibitory inputs to VP-secreting neurons follows activation of carotid chemoreceptors and peripheral baroreceptors respectively. ${ }^{7.23}$ The $A 1$ noradrenergic afferents originating in the caudal ventrolateral medulla (CVLM) display a pattern of innervation that is both specific and excit- 
atory to s.o.n. VP neurons. The Al - s.o.n. projection is thus ideally suited for central transmission of chemoreceptor information that is facilitatory to vasopressin neurons through the activation of an $\alpha-1$ adrenoreceptor. Indeed, lesions of the Al region abolish chemoreceptor induced activation of vasopressinergic neurons. ${ }^{3}$ The Al - s.o.n. pathway has also been implicated in mediating the inhibitory baroreceptor input to VP neurons on the basis of the $\beta$-adrenoreceptor depressant action of noradrenaline. ${ }^{24,25}$ However, 6-hydroxydopamine-induced depletion of terminal catecholamine fluorescence in the s.o.n. does not interfere with the depressant response of VP neurons consequent to baroreceptor activation. ${ }^{4}$

In view of these observations the GABAergic pathway from the DB that is inhibitory to the VP neurons may be considered as a candidate in mediating baroreceptor information to the s.o.n. This notion is supported by findings of the present study which demonstrate the ability of locally applied bicuculline but not catecholamine or glycine antagonists to reversibly block the baroreceptor-induced inhibition of vasopressin neurons. The pathways whereby baroreceptor information is conveyed from the brainstem to DB neurons are not well defined and remain an area of future endeavour. However, the nucleus tractus solitarius (NTS), the site of the first synapse in the DNS of baroreceptor afferents, is known to project to more rostral structures and in particular to the locus coeruleus. ${ }^{26.27}$ Lesions of the locus coeruleus do interfere with the baroreceptor input to the s.o.n. vasopresinergic neurons. ${ }^{3}$ In order to reconcile these observations with our own findings it is proposed that the

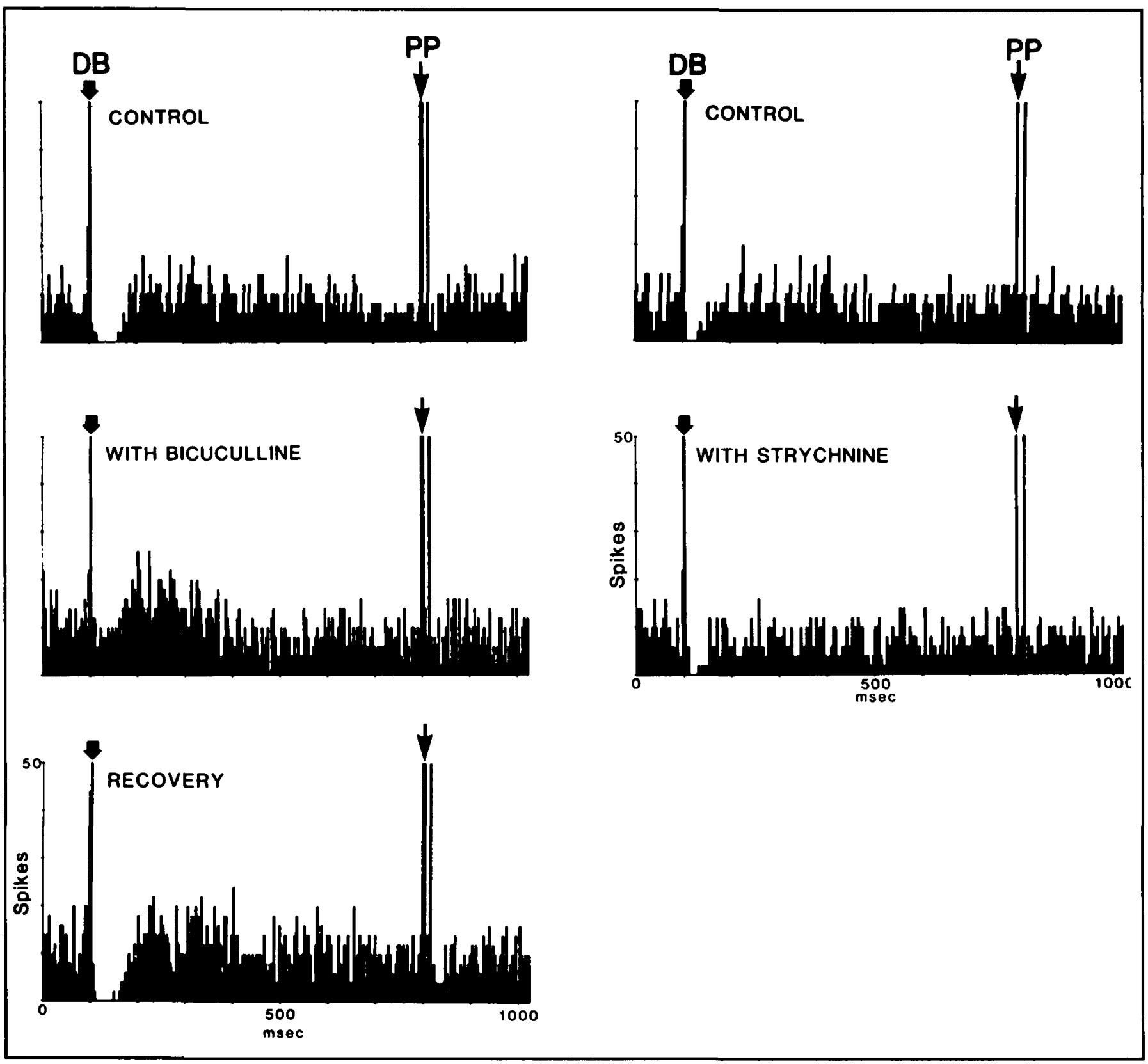

Figure 4 - On the left, peristimulus histograms from a VP neuron illustrate control responses to DB stimulation (top), abolition of DB responses in the presence of bicuculline methiodide ( $100 \mu \mathrm{m}$, middle row) and recovery of the response (lowest record). Recovery is achieved within 4 minutes. On the right, in contrast, strychnine $(100 \mu \mathrm{m})$ does not influence the decrease in excitability of another VP neuron following $D B$ stimulation. 
locus coeruleus mediates baroreceptor activity to vasopressinsecreting neurons but does so indirectly through the DB (Figure 6). Such a proposal derives support from anatomical studies which reveal a locus coeruleus projection to the $\mathrm{DB}^{28.29}$ and our own observations that a population of DB neurons projecting to the s.o.n. increase their firing during baroreceptor activation, co-inciding with the suppression of s.o.n. vasopressin neurons. ${ }^{30}$

In conclusion, the present study suggests that a GABAergic pathway from the diagonal band of Broca mediates, in large part, peripheral baroreceptor information to the s.o.n. vasopressin-secreting neurons and that these DB afferents to the hypothalamic supraoptic nucleus selectively inhibit the release of vasopressin from the neurohypophysis. This DB - s.o.n. projection may assume increasing importance in view of the recent marked change in our appreciation of the importance of vasopressin in cardiovascular function in general and hypertension in particular. ${ }^{31}$ The DB may through its control of vasopressin release exert a widespread influence in those forms of experimental hypertension where abnormalities in the central control of baroreceptor function have been implicated but not yet established.

\section{ACKNOWLEDGEMENTS}

This work was supported by the Medical Research Council of Canada. We thank J. Rogers and J. Dufresne for technical assistance, S. Lafontaine for software development and Gwen Peard for typing this manuscript. J.H. Jhamandas is a Centennial Fellow of the M.R.C.

\section{REFERENCES}

1. Poulain DA, Wakerley JB. Electrophysiology of hypothalamic magnocellular neurones secreting oxytocin and vasopressin. Neuroscience 1982; 7: 773-808.

2. Brimble MJ, Dyball REJ. Characterization of responses of oxytocinand vasopressin-secreting neurones in the supraoptic nucleus to osmotic stimulation. J Physiol (Lond) 1983; 271: 253-271.

3. Banks D, Harris MC. Lesions of the locus coeruleus abolish baroreceptor induced depression of supraoptic neurons in the rat. J Physiol (Lond) 1984; 355: 383-398.

4. Day TA, Renaud LP. Electrophysiological evidence that noradrenergic afferents selectively facilitate the activity of supraoptic vasopressin neurons. Brain Res 1984; 303: 233-240.

5. Day TA, Ferguson AV, Renaud LP. Facilitatory influences of noradrenergic afferents on the excitability of rat paraventricular nucleus neurosecretory cells. J Physiol (Lond) 1984; 355: 237-249.

6. Day TA, Randle JCR, Renaud LP. Opposing alpha- and betaadrenergic mechanisms mediate dose dependent actions of noradrenaline on supraoptic vasopressin neurons in vivo. Brain Res 1985; 358: 171-179.

7. Harris MC. Effects of chemoreceptor and baroreceptor stimulation on the discharge of hypothalamic supraoptic neurones in rats. J Endocrinol 1979; 82: 115-125.

8. Meyer DK, Oertel WH, Brownstein MJ. Deafferentiation studies on the glutamic acid decarboxylase content of the supraoptic nucleus of the rat. Brain Res 1980; 200: 165-168.

9. Perez de la Mora M, Possani LD, Tapia R. Demonstration of central $\gamma$-aminobutyric-containing nerve terminals by means of antibodies against glutamate decarboxylase. Neuroscience 1981; 6: $875-895$

10. Bioulac B, Gaffori O, Harris M, et al. Effects of acetylocholine sodium glutamate and GABA on the discharge of supraoptic neurons in the rat. Brain Res 1978; 154: 159-162.

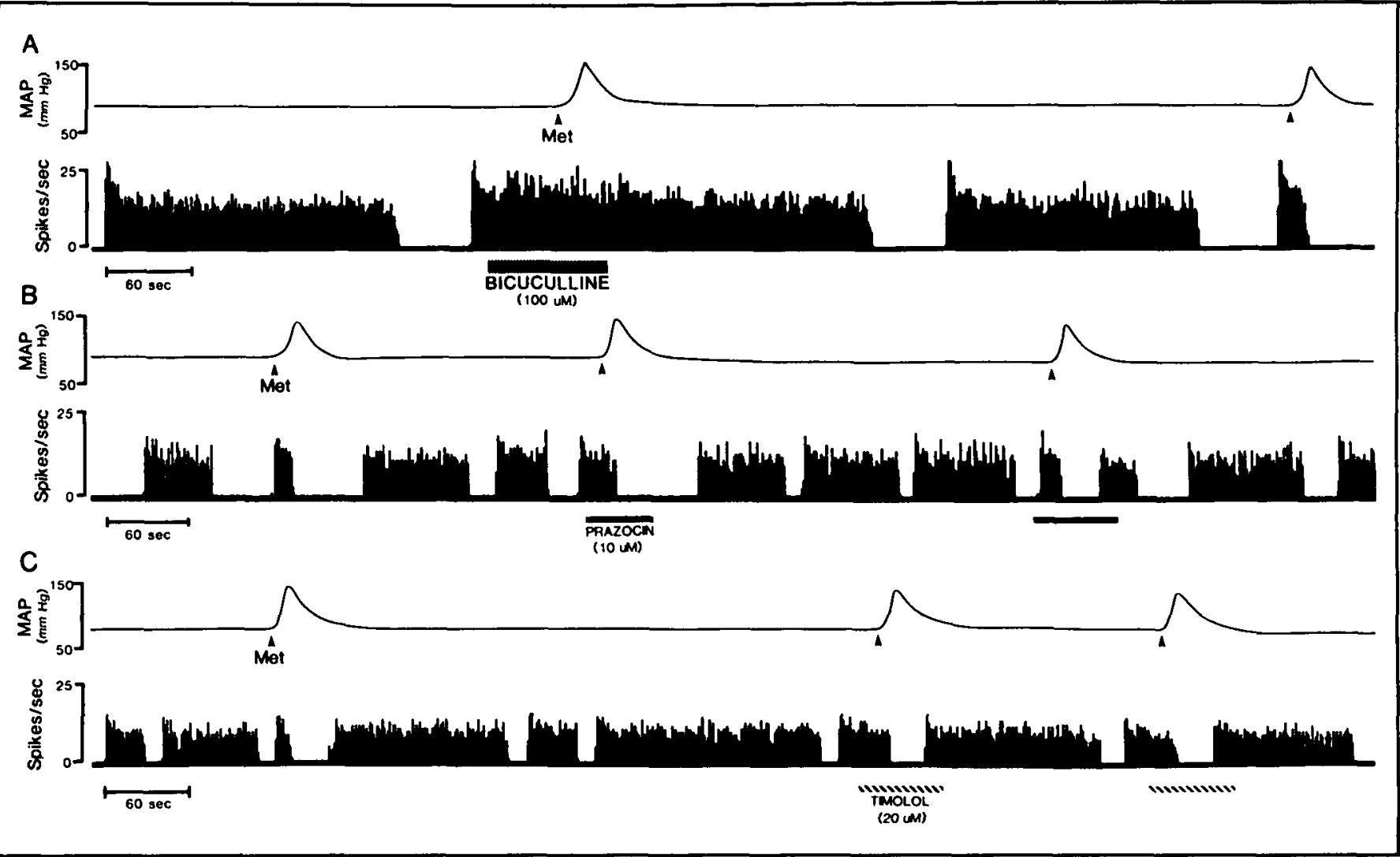

Figure 5 - Ratemeter records from three phasically firing VP neurons demonstrate a typical reduction in firing induced by a rise in mean arterial pressure (MAP upper traces) consequent to brief intravenous administration of metaraminol (Met, arrow). Locally applied bicuculline methiodide (100 $\mu m$ ) by pressure ejection (horizontal line) reversibly abolishes the metaraminol-induced responses (A). No such abolition is evident in presence of either prazosin (10 $\mu M$, solid line) or timolol (20 $\mu M$, stippled line) applications $(B, C)$. 


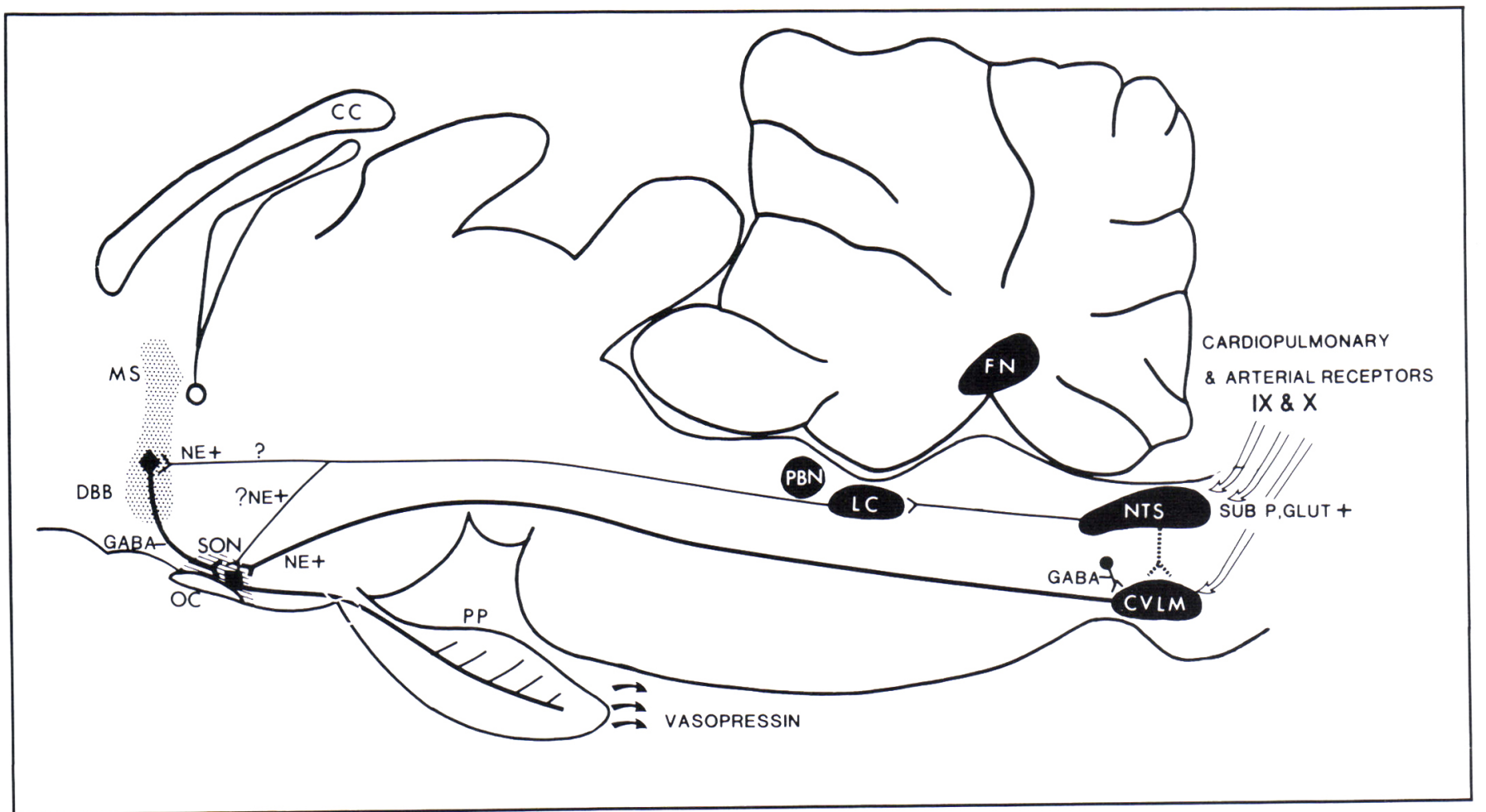

Figure 6-Proposed central neural network whereby peripheral baroreceptor information is conveyed to hypothalamic vasopressin-secreting neurons. Ascending catecholaminergic projection from the locus coeruleus $(L C)$ may indirectly inhibit supraoptic vasopressinergic neurons through a GABA interneuron located in the diagonal band of Broca $(D B)$. A direct excitatory pathway from the caudal ventrolateral medulla $(C V L M)$ may mediate the chemoreceptor input to the vasopressin neurons of the supraoptic mucleus. For details see DISCUSSION in text. Abbreviations: CC, corpus callosum; MS, medial septum; PP, posterior pituitary; PBN, parabrachial nucleus; FN. fastigial nucleus; NTS, nucleus of tractus solitarius, NE. noradrenaline; GABA, $\gamma$-aminobutyric acid; GLUT, glutamate. Sub P, substance $P$; $+=$ excitatory: $-=$ inhibitory.

11. Arnauld E, Cirino M. Layton BS, et al. Contrasting actions of amino acids acetylcholine noradrenaline and leucine enkephalin on the excitability of supraoptic vasopressin-secreting neurons. Neuroendocrinol 1983; 36: 187-196.

12. Poulain DA, Ellendorf F, Vincent JD. Septal connections with identified oxytocin and vasopressin neurones in the supraoptic nucleus of the rat. An electrophysiological investigation. Neuroscience 1980; 5: 379-387.

13. Cirino M, Renaud LP. Influence of lateral septum and amygdala stimulation of the excitability of hypothalamic supraoptic neurons. An electrophysiological study in the rat. Brain Res 1985; 326: 357-361.

14. Shibuki K. Supraoptic neurosecretory cells: synaptic inputs from the nucleus accumbens in the rat. Exp Brain Res 1984; 53: 341-348.

15. Zaborszky L, Leranth C. Makara GB, et al. Quantitative studies on the supraoptic nucleus in the rat. II Afferent fiber connections. Exp Brain Res 1975; 22: 525-540.

16. Tribollet E. Armstrong WE. Dubois-Dauphin M. et al. Extrahypothalamic afferent inputs to the supraoptic nucleus area of the rat as determined by retrograde and anterograde tracing techniques. Neuroscience 1985; 15: 135-138.

17. Krnjevic K. Chemical nature of synaptic transmission in vertebrates. Physiol Rev 1974; 54: 418-540.

18. Tappaz ML, Wassef $M$, Oertel WH, et al. Light- and electronmicroscopic immunocy tochemistry of glutamic acid decarboxylase (GAD) in the basal hypothalamus: morphological evidence for neuroendocrine gamma-aminobutyrate (GABA). Neuroscience 1983; 9: 271-287.

19. Nagai T, McGeer PL, McGeer EG. Distribution of GABA-T intensive neurons in the rat forebrain and midbrain. J Comp Neurol 1983; $218: 220-238$.

20. Panula P, Revuelta AV, Cheney DL, et al. An immunohistochemical study on the location of GABAergic neurons in rat septum. J
Comp Neurol 1984; 222: 69-80.

21. Randle JCR, Bourque CW, Renaud LP. Spontaneous and evoked IPSPs in rat supraoptic nucleus neurosecretory neurons in vitro. Proc Can Fed Biol Sci 1985; $28: 93$.

22. Knepel W, Nutto D. Hertting G. Evidence for involvement of a GABA-mediated inhibition in hypovolaemia-induced vasopressin release. Pflugers Arch 1980; 388: 177-183.

23. Yamashita H. Effect of baro- and chemoreceptor activation on supraoptic nuclei neurons in the hypothalamus. Brain Res 1977: 126: $551-556$.

24. Barker JL, Crayton JW, Nicoll RA. Noradrenaline and acetylcholine responses of supraoptic neurosecretory cells. J Physiol (Lond) 1971; 218: 19-32.

25. Blessing WW, Sved AF, Reis DJ. Destruction of noradrenergic neurons in rabbit brainstem elevates plasma vasopressin causing hypertension. Science 1982; 217: 661-663.

26. Sakai K, Tourets M, Salvert D, et al. Afferents to the cat locus coeruleus and rostral raphe nuclei as visualized by horseradish peroxidase techniques. In: Grattini S Pujol JF \& Samarin, $R$. eds. Interactions Between Putative Neurotransmitters in the Brain. New York: Raven Press 1978; 473-478.

27. Sawchenko PE, Swanson LW. The organization of noradrenergic pathways from the brainstem to the paraventricular and supraoptic nuclei in the rat. Brain Res Rev 1982; 4: 275-325.

28. Jones BE, Moore RY. Ascending projections of the locus coeruleus in the rat. II Autoradiographic study. Brain Res 1977: 127:23-53.

29. Ward DG, Lefcourt AM, Gann DS. Neurons in the dorsal pons process information about changes in venous return and in arterial pressure. Brain Res 1980; 181: 75-78.

30. Jhamandas JH, Renaud LP. Diagonal band neurons may mediate arterial baroreceptor input to hypothalamic vasopressin-secreting neurons. Neurosci Lett 1986; 65: 214-218.

31. Rossi NF, Schrier RW. Role of arginine vasopressin in regulation of systemic arterial pressure. Ann Rev Med 1986; 37: 13-20. 